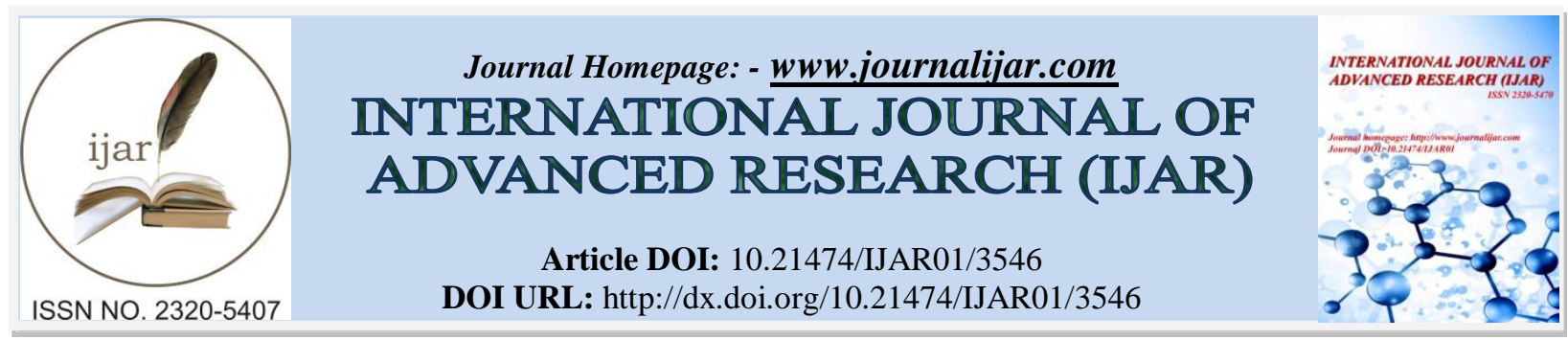

RESEARCH ARTICLE

\title{
POLYPHENOLS CONTENT AND EVALUATION OF ANTIOXIDANT ACTIVITY OF ANACYCLUSPYRETHRUM(L.) LAG. FROM TIMAHDITE A MOROCCAN MIDDLE ATLAS REGION.
}

\section{Ali CHERRAT ${ }^{1,2}$, Smail AMALICH ${ }^{1,2}$, Mohamed REGRAGUI ${ }^{1,2}$, Amal BOUZOUBAE ${ }^{1,2}$, Mohamed ELAMRANI $^{3}$, Malika MAHJOUBI ${ }^{1,2}$, Mohamed BOURAKHOUADAR ${ }^{1,2}$ and Touriya ZAIR ${ }^{1,2}$.}

1. Research team of Chemistry Bioactive Moleculesand the Environment, University Moulay Ismail, Faculty of Sciences, BP 11201, Zitoune, Meknès, Morocco.

2. Laboratory of Materials Chemistryand Biotechnologyof Natural Pproducts, University Moulay Ismail, Faculty of Sciences, B.P. 11201 Zitoune, Meknès, Morocco.

3. Food Units of Technology and Biochemistry, National school of Agriculture, BPS/40, Meknes, Morocco.

\section{Manuscript Info}

Manuscript History

Received: 01 January 2017

Final Accepted: 05 February 2017

Published: March 2017

Key words:-

Anacyclus pyrethrum, Timahdite, polyphenolics content, Antioxidant activity.

\section{Abstract}

As part of valorisation of medicinal and aromatic plants from Timahdite, a region located in Moroccan Middle Atlas, we focused our study on an endemic species which belongstoAsteraceae family: Anacyclus pyrethrum L. This species, widely used by local people in traditional pharmacopeia, was chosen to conduct phytochemical studies and to assess the antioxidant activity of its roots, leaves and flowers extracts.

Thus, the plant was harvested in May 2014. The selected organs (roots, leaves and flowers) of Anacyclus pyrethrum were sorted, cleaned and dried separately. Then, they were reduced into powder and stored away from light in a cool and dry place until use. Each organ was subjected to a phytochemical screening in order to qualitatively highlight its secondary metabolites.

This qualitative analysis shows that roots are rich in alkaloids while the aerial parts (leaves and flowers) are rich in tannins and flavonoids. Extraction of total polyphenols was performed by maceration using methanol / water (70/30) as solvent. Yields were $2.30 \%$ for roots, $3.3 \%$ for leaves and $3.8 \%$ for flowers.

Then, fractionation of hydro-methanol crude extract was carried out using successively three organic solvents of increasing polarity: chloroform, ethyl acetate and butanol. Quantitative analysis of total polyphenols conducted with Folin-Ciocalteu reagent showed that hydro-methanol crude extracts are richer in phenolic compounds than other fractions.

Antioxidant activity of crude extracts determined through DPPH test was spectrophotometrically quantified and values of the half-maximal inhibitory concentrations (IC50) were graphically determined. These values are $77.62 \mu$ ggallic acid equivalent (GAE) / $\mathrm{ml}$ for flowers, $94.18 \mu \mathrm{g} / \mathrm{ml}$ for leaves and $145.81 \mu \mathrm{g} / \mathrm{ml}$ for roots, while $46.79 \mu \mathrm{g} / \mathrm{ml}$ was found for ascorbic acid which was used as standard.

Finally, a correlation was observed between total polyphenols content and antioxidant capacity determined by DPPH method: Aerial parts

Corresponding Author:- Ali CHERRAT.

Address:- Research team of Chemistry Bioactive Moleculesand the Environment, University Moulay 
(leafy stem and flowers) richer in polyphenols exert a better antioxidant activity compared to roots.

Copy Right, IJAR, 2017,. All rights reserved.

\section{Introduction:-}

These last decades have been marked by the widespread use of synthetic products in various industrial fields. Through years, thispractice in the case of synthetic antioxidant molecules has often led to potential toxicological risks. Now, their use is reconsidered by international organizations and new plants are sought asa source of natural antioxidants [1,2]. Thanks to their properties, these natural antioxidants attract more interest in various fields. They are used to prevent and to treat cancer, inflammatory and cardiovascular diseases [3]. They are also used as additives in food, pharmaceutical and cosmetic products [1]. Thus, scientific research has been developed with the aim to extract, identify and quantify antioxidant compounds from natural sources such as medicinal plants and food products. In this quest for safe natural antioxidants, polyphenolics, which are widespread natural plant compounds, are of great interestbecause of their beneficial effects on health [4].

With the aim to find promising phenolic compounds, our research focuses onAnacycluspyrethrumwhichis a Moroccan and Algerian endemic species belonging to Asteraceaefamily [5]. This perennial plant is widely prevalent in Moroccan Middle Atlas [6]. It is a40 to $60 \mathrm{~cm}$-height species which is characterized by long and thick roots. Its numerous simple or ramified stems lie on the ground and bear pinnate, alternate, finely cut, delicate and pubescent leaves. Its yellow-heart flowers are composed of white petals inside and purple petals outside. The species is well appreciated as a remedy against toothache [5], digestive disorders [8]. It also acts as a warming agent to enhance women fecundity and constitute a tonic agent for the nervous system [9]. Anacyclus pyrethrum is also used to treat cough, cold as well as heart, lung and digestive diseases [10].For this medicinal value, this plant was selected for the present study. Moreover,reviewon this species showed that its chemistry remains insufficiently studied. According to our knowledge, no research work was conducted on the aerial parts of the plant.Thus, our work aims to contribute to a complete phytochemical study of A. pyrethrum and to contribute totheexplanationof its various activities. We focused our interest on the wild species which particularly grows in Timahdite's forests, at altitudes ranging from 400 to $3100 \mathrm{~m}$. [11].

The aim of our work is to quantify Anacyclus pyrethrum 'sphenolics in the extractsofthree organs and to assess their antioxidant power by DPPH method.

\section{Material and methods:- \\ plant materiel}

Anacyclus pyrethrum was harvested in May 2014 at $1800 \mathrm{~m}$ of altitude in Timahdite, a region located at $30 \mathrm{~km}$ south from Azrou. Samples were harvested with their roots, stems, leaves and flowers in order to make their identification easier. This plant identification was conducted in the laboratory of Botany and Plant Ecology at the Scientific Institute of Rabat by Professor MOHAMED IBN TATOU. Samples of different organs (roots, flowers and leaves) were cleaned, shade dried at room temperature and then stored away from light until use.

\section{phytochemical screening :-}

Plants organs (roots, leaves and flowers) were powdered with an electric grinder. After this step, chemical composition of the drug was determined by a phytochemical study based on solubility tests, colour and precipitation reactions and also by observations under ultraviolet light.

The target phytochemical groups in these tests include: alkaloids, polyphenols (flavonoids, anthocyanins, tannins, ...), saponins, coumarins, sterols, terpenes, mucilage, carotenoids, reducing sugars (oses and holosides)

$>\quad$ Research on alkaloids was performed using Dragendorff and Mayer's reagents which are reagents for general characterization of alkaloids [12].

$>$ Characterization of tannins was carried out with Iron chloride reagent. The differentiation between gallic and catechictannins was shown thanks to Stiasny'sreaction[13].

$>$ Identification of flavonoids was performed by cyanidin test [14].

$>$ Research of saponosides was quantitatively determined by calculating the foam index after shaking the aqueous extract [15].

$>$ Anthraquinones were identified by Borntrager's test [16]. 
$>$ Sterols and terpeneswere highlighted by Liebermann-Burchard's test [17].

$>$ Coumarins were demonstrated by UV fluorescence at $365 \mathrm{~nm}$ [13].

$>$ Mucilageswereindicated by the presence of a flocculent precipitate after adding ethyl ether in a test tube containing plant's decoction [18].

Phytochemical screening was carried out separately on plant'sleaves, flowers and roots.

\section{Preparation of extracts:-}

Test samples composed of $30 \mathrm{~g}$ powder of root, leaves and flowers of Anacyclus pyrethrum was macerated in a hydro-alcoholic mixture (methanol / water 70/30: v / v) with magnetic stirring for 30min. The mixture was then stored in the dark for 24 hours at room temperature. The obtained solution was filtered on filter paper and the filtrate was concentrated under vacuum at $50^{\circ} \mathrm{C}$ with a Büchi-type rotary evaporator [19]. The dry extract was then weighed, labelled and stored at $4^{\circ} \mathrm{C}$ until use.

\section{Fractionation:-}

Polyphenols extraction was performed according to Bruneton's method [15] with a slight modification. It is based on polyphenols' degree of solubility in organic solvents. Fractionation of crude hydro-methanol extracts was carried out by successive use of four organic solvents with different polarity: petroleum ether, chloroform, ethyl acetate and butanol.

In addition to the hydro-methanol crude extract (F0), four fractions wereselected for further work: chloroform fraction (F1), ethyl acetate fraction (F2), butanol fraction (F3) and residual aqueous fraction (F4). The different extracts were kept cold away from light until use. Picture 1 summarises fractionationsteps of the crude extracts.

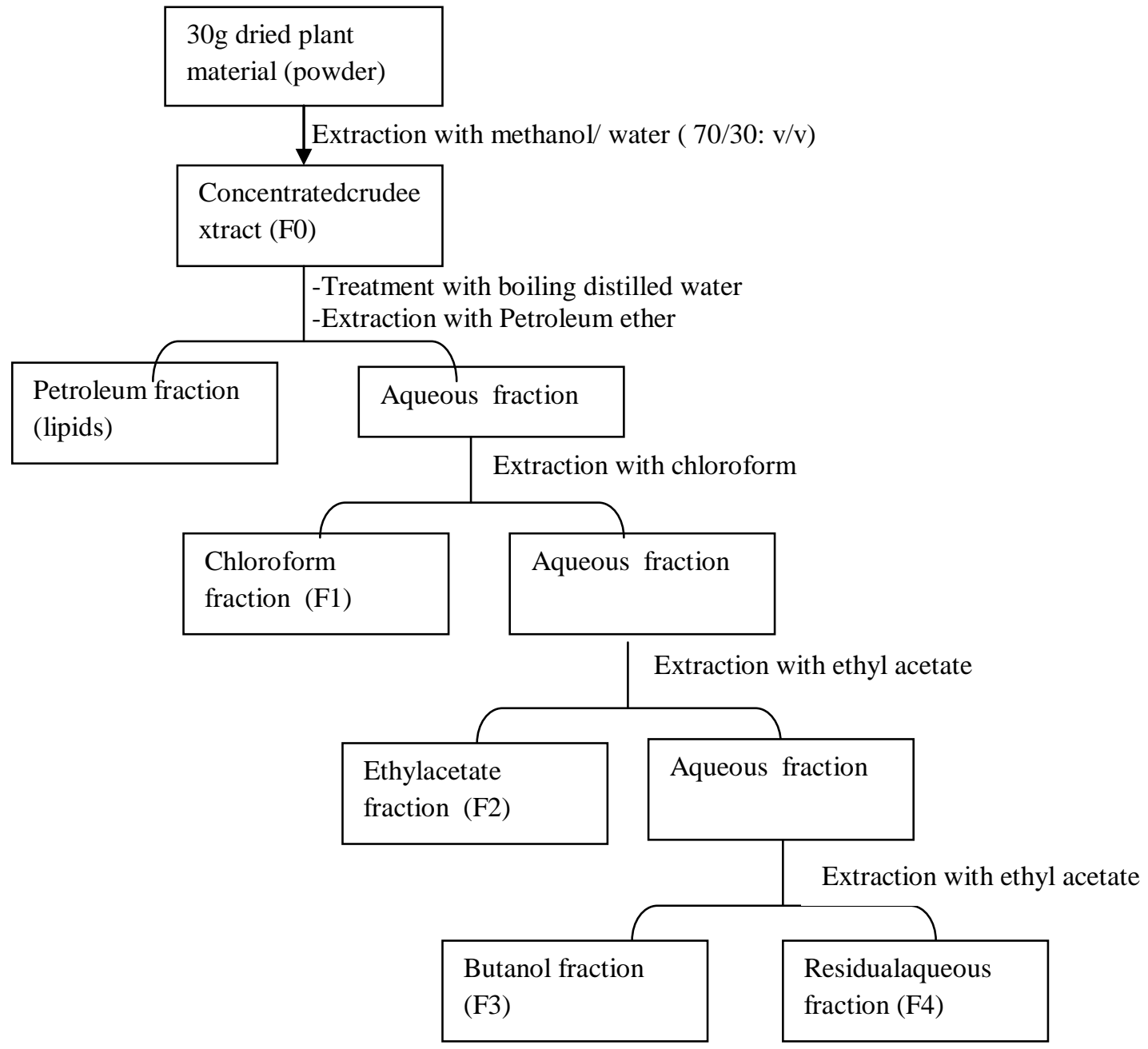

Picture 1:- Fractionation steps of crude extracts. 


\section{Determinationof Total Phenols Content :-}

Total polyphenol content of A. pyrethrum's crude extracts was determined by Folin-Ciocalteu's method [20]. In a 100 ml-volumetric flask, $40 \mathrm{ml}$ of each extract were mixed with $1.5 \mathrm{ml}$ of an aqueous solution of sodium bicarbonate $\left(\mathrm{Na}_{2} \mathrm{CO}_{3}\right)$ at $10 \%$ and $1.5 \mathrm{ml}$ of Folin-Ciocalteu reagent (10fold diluted). Then the flask was supplemented with distilled water. The mixture was stirred and incubated in the dark at room temperature for 30 minutes. The reading step was performed against ablank using a spectrophotometer (UV mini-1240) at $765 \mathrm{~nm}$. A standard curve with gallic acid as positive control was established in parallel under the same operating conditions. Results are expressed as milligrams of gallic acid equivalent per gram of extract (mg GAE / g).

\section{Determination of flavonoids contents:-}

Total flavonoids content of $A$. pyrethrum's extracts was determined according to aluminumtrichloride method. The mixture was stirred and then incubated in the dark at room temperature for 30 minutes. A blank is prepared by replacing the extracts by methanol and the absorbance is read at $433 \mathrm{~nm}$ with a UV spectrophotometer. Results are expressed as mg of quercetin equivalent / gram of dry plant material. Quercetin calibration curve served as a standard.

\section{Assessment of antioxidantactivity :- \\ Dpph Test:- \\ Principle:-}

DPPH (2,2-diphenyl-1-picrylhydrasyl) is generally the most widely used substrate for rapid and direct assessment of antioxidant activity thanks to the stability of its free radical form and the simplicity of the analysis. This method is based on the measurement of antioxidants' ability to scavenge the DPPH radical [21]. Indeed, the latter is characterized by its ability to generate stable free radicals. This stability is due to the relocation of free electrons in the molecule, this relocation leads to a violet blue colour which is characteristic of the DPPH solution. Evaluation of antioxidant effectiveness isspectrophotometrically assessed at 515nmthrough the decrease of the blue colour due to recombination of DPPH radicals [22]. In the presence of free radical scavengers, purple-coloured DPPH $(2,2-$ diphenyl-1- picrylhydrazyl), is reduced into 2,2-diphenyl hydrazine -1- picrylwhich presents a yellow colour in the presence of free radical compounds [23] .

\section{Protocole:-}

Ethanol solutions of ethyl acetate fraction were prepared.The following concentrations were obtained: 16; 32; 48; $64 ; 80 ; 96 ; 112 ; 128 ; 144 ; 160 ; 176$ and $192 \mu \mathrm{g} / \mathrm{ml} .200 \mu \mathrm{l}$ of each ethanol solution were added to $1.8 \mathrm{ml}$ of DPPH* solution which is also prepared in ethanol $(0.024 \mathrm{~g} / \mathrm{l})$. In parallel, a negative control was prepared by mixing $200 \mu \mathrm{l}$ of ethanol with $1.8 \mathrm{ml}$ of ethanol DPPH* solution. Absorbance was read against a blank at $515 \mathrm{~nm}$ after 30 min of incubation in the dark at room temperature. Ascorbic acid solution was used as a positive control. Absorbance was read in the same conditions for samples and controls. The test is repeated three times. Results are expressed as DPPH* reduction percentage. This percentage is calculated using the following formula:

$\% \mathbf{P}=\left[\left(\mathbf{A}_{\mathrm{bl}}-\mathbf{A}_{\mathrm{s}}\right) / \mathbf{A}_{\mathrm{bl}}\right] \times \mathbf{1 0 0}$

$\mathrm{P}$ : DPPH* reduction percentage; $\mathrm{A}_{\mathrm{bl}}$ : blank absorbance; As : sample absorbance

\section{Results and discussion:-}

\section{phytochemical tests :-}

Results of phytochemical tests are gathered in table 1 .

Table1:- Results of phytochemical screening of Anacyclus pyrethrum 'shydro-methanolextracts

\begin{tabular}{|l|l|l|l|}
\hline \multirow{2}{*}{ Chemical class } & Organs & \multicolumn{2}{l|}{} \\
\cline { 2 - 4 } & Roots (R) & Leaves (LS) & Flowers (F) \\
\hline Alkaloids & +++ & + & + \\
\hline Gallic tannins & + & + & + \\
\hline Catechic tannins & + & ++ & +++ \\
\hline Flavonoids & - & ++ & +++ \\
\hline Anthocyans & - & - & - \\
\hline Leucoanthocyans & +++ & ++ & ++ \\
\hline Saponosides & + & + & - \\
\hline Free anthraceniccompounds & - & - & - \\
\hline Combinedanthraceniccompounds & +++ & ++ & ++ \\
\hline
\end{tabular}




\begin{tabular}{|l|l|l|l|}
\hline Coumarins & + & ++ & + \\
\hline Carotenoids & - & - & - \\
\hline Sterols and triterpenes & + & ++ & + \\
\hline Reducingcompound & +++ & ++ & ++ \\
\hline Oses et holosids & +++ & ++ & ++ \\
\hline Mucilages & +++ & + & + \\
\hline Narcotics & - & - & - \\
\hline
\end{tabular}

$(+++)$ : strong reaction; $(++)$ : moderate reaction; $(+)$ : weak reaction ;(-): no reaction

Results of phytochemical tests have shown that:

$>$ Alkaloids are present in all three parts of the plant, but in small quantities in the aerial parts (leaves and flowers) compared to roots.

$>$ Flavonoids are not detected in roots, but leaves contain mainly flavanols and flavanonols (red colour) while flowers essentially contain flavones (orange-pink colour).

$>$ Tannins: Based on the colour obtained with $\mathrm{FeCl}_{3}$ reagent, different parts of this species contain gallic tannin. Catechic tannins are less important in roots compared to leaves and flowers. Their presence is confirmed by Stiasny's reaction.

$>$ Saponosides were detected and foams indices show that saponins content is low $(1.1 \mathrm{~cm})$ in leaves and roots. They are clearly absent in flowers.

$>$ Sterols and terpenes are detected in a higher content in leaves compared to flowers and roots. A violet colour appears and then turns green.

$>$ Coumarins presence is remarked thanks to fluorescent spots observed during qualitative analysis.

$>$ Reducing compounds are present in large amount in the three parts of the plant.

$>$ Finally, it should be noted that carotenoids, narcotics, free anthracenic compounds (anthraquinone) and anthocyans are absent or rare in all studied parts of the plant.

The roots of $A$. pyrethrum mainly contain alkaloids and tannins. Similar results have been shown by Bellakhdar, 1996 [24], Hmamouchi, 1999,[25],Center for Mediterranean Cooperation, 2005[26], Selles et al., 2012[27], Limbachia\&Jadhav, 2012 [28]). They also contain mucilage. The presence of mucilage in the roots of $A$. pyrethrum allowed us to note the viscous character of the extracts. During our phytochemical tests, we have demonstrated the presence of coumarins, sterols and triterpenes in the roots of A. pyrethrum but in small amount. These results are consistent with the previous works of Hamimed, 2009 [29]; Selleset al., 2012[30]. The roots of A. pyrethrum also contain oses, holosides and reducing compounds. This was highlighted by (Selles C., 2012) [30]. Hence, the chemical composition of the roots of $A$. pyrethrum has proved to be interesting and rich incompounds known as bioactive molecules (Hamimed, 2009 [29]; Christian, 2013[31]). The overall results justify the various activities of this plant including the use of part of its chemical compounds as alternative to synthetic antioxidants.

Extraction yiedls :-

Yields of crude hydro-methanol extracts from roots, leaves and flowers are respectively: $2.3 \%, 3.3 \%$ and $3.3 \%$ (Table 2).

For crude extracts fractionation, results show that butanol fraction has the highest yields $(1.93 \%, 3.2 \%$ and $3.7 \%)$ followed by the aqueous fraction $(1.33 \% ; 2.9 \%$ and $3.2 \%)$ and then the ethyl acetate fraction $(1.23 \%, 2.23 \%$ and $2.4 \%$ ). On the other side, the lowest yield was obtained with the chloroform fraction:0.76\%, $1.8 \%$ and $2.1 \%$ respectively for roots, leaves and flowers(Table2).

Table 2:- $\quad$ Yields of polyphenol extracts and fractions obtained from Anacyclus pyrethrum'sorgans

\begin{tabular}{|l|l|l|l|}
\hline $\begin{array}{c}\text { Extracts and fractions from } \\
\text { A. pyrethrum'sorgans }\end{array}$ & \multicolumn{2}{|l|}{ Yields (\%) } & Flowers (F) \\
\cline { 2 - 4 } & Roots (R) & leaves (LS) & $3.8 \%$ \\
\hline Crudehydro-methanolextract & $2.30 \%$ & $3.3 \%$ & $2.1 \%$ \\
\hline Chloroform fraction & $0.76 \%$ & $1.8 \%$ & $2.4 \%$ \\
\hline Ethylacetate fraction & $1.23 \%$ & $2.23 \%$ & $3.7 \%$ \\
\hline Butanol fraction & $1.93 \%$ & $3.2 \%$ & $3.2 \%$ \\
\hline Aqueous fraction & $1.33 \%$ & $2.9 \%$ & \\
\hline
\end{tabular}

total phénol content 
UV / Visible spectrophotometry allowedto quantify polyphenols in all extracts and fractions. Results are shown in Table 3.

Table 3:- Polyphenol content of A.pyrethrum'sextractsand fractions expressed in milligrams equivalents gallic acid per gram of extract (mg GAE/g of extract)

\begin{tabular}{|l|l|l|l|}
\hline \multirow{2}{*}{ Extracts } & \multicolumn{2}{l|}{ Polyphenol content in mg GA eq /g of extract) } \\
\cline { 2 - 4 } & Flowers & Leaves & Roots \\
\hline hydro-methanolextract $\left(\mathrm{F}_{0}\right)$ & $21.84 \pm 2.41$ & $14.23 \pm 1.44$ & $7.83 \pm 1.18$ \\
\hline Chloroform fraction $\left(\mathrm{F}_{1}\right)$ & $13.49 \pm 1.51$ & $5.67 \pm 0.48$ & $4.94 \pm 0.21$ \\
\hline ethylacetate fraction $\left(\mathrm{F}_{2}\right)$ & $14.20 \pm 1.40$ & $10.23 \pm 1.34$ & $5.94 \pm 1.21$ \\
\hline butanol fraction $\left(\mathrm{F}_{3}\right)$ & $19.84 \pm 1.81$ & $12.15 \pm 1.18$ & $6.15 \pm 1.70$ \\
\hline residual fraction $\left(\mathrm{F}_{4}\right)$ & $16.12 \pm 0.09$ & $11.85 \pm 1.09$ & $5.88 \pm 0.63$ \\
\hline
\end{tabular}

For all parts of the studied plant, we noticed the variability of total phenols contents (Table 3 ). The highest content was found in flowers. It varies between $13.49 \mathrm{mg}$ and $21.84 \mathrm{mg}$ of gallic acid equivalent per gram of extract followed by the leaves with a content ranging between $5.67 \mathrm{mg}$ and $14.23 \mathrm{mg} \mathrm{GA} \mathrm{eq/} \mathrm{g}$ of extract. Polyphenol content of roots varies between $4.94 \mathrm{mg}$ and $7.83 \mathrm{mgGA}$ eq / $\mathrm{g}$ of extract.

We also found that methanol crude extracts contain relatively high concentrations of polyphenols compared to other fractions. Phenol content of a plant depends on a number of factors such as climatic conditions, time of harvest, solvent of extraction, storage conditions [24].

\section{flavonoids content:-}

Flavonoid content in hydro-methanol extracts obtained from A.pyrethrum's organs arerecorded in picture 2.

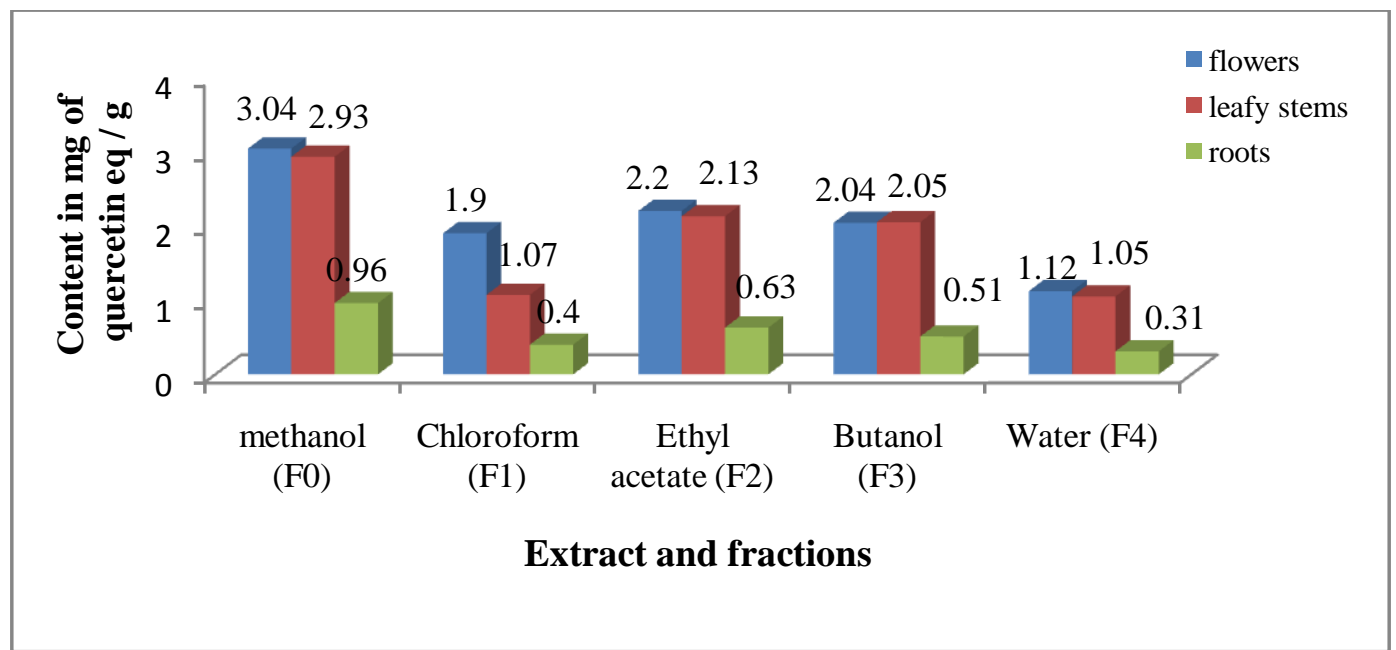

Picture 2:- Flavonoid contents in flowers', leaves' and roots' extracts and fractions of Anacyclus pyrethrum Concerning flavonoid, the highest contentis recordedinflowers' hydro-methanol extract with a value equal to $3.4 \mathrm{mg}$ of quercetineq / $\mathrm{g}$ of dried plant material followed by the leaves'hydro-methanol extract with $2.93 \mathrm{mg}$ of quercetineq / $\mathrm{g}$ and finally roots' hydro-methanol extractwith $0.96 \mathrm{mg}$ of quercetineq / $\mathrm{g}$ dried plant material .

We can deduce that the crude extracts from flowers and leaves of A. pyrethrum. are the richest in flavonoids.

\section{Antiioxidant activity:-}

Values obtained from DPPH test allowed to establish curves on picture 3. 


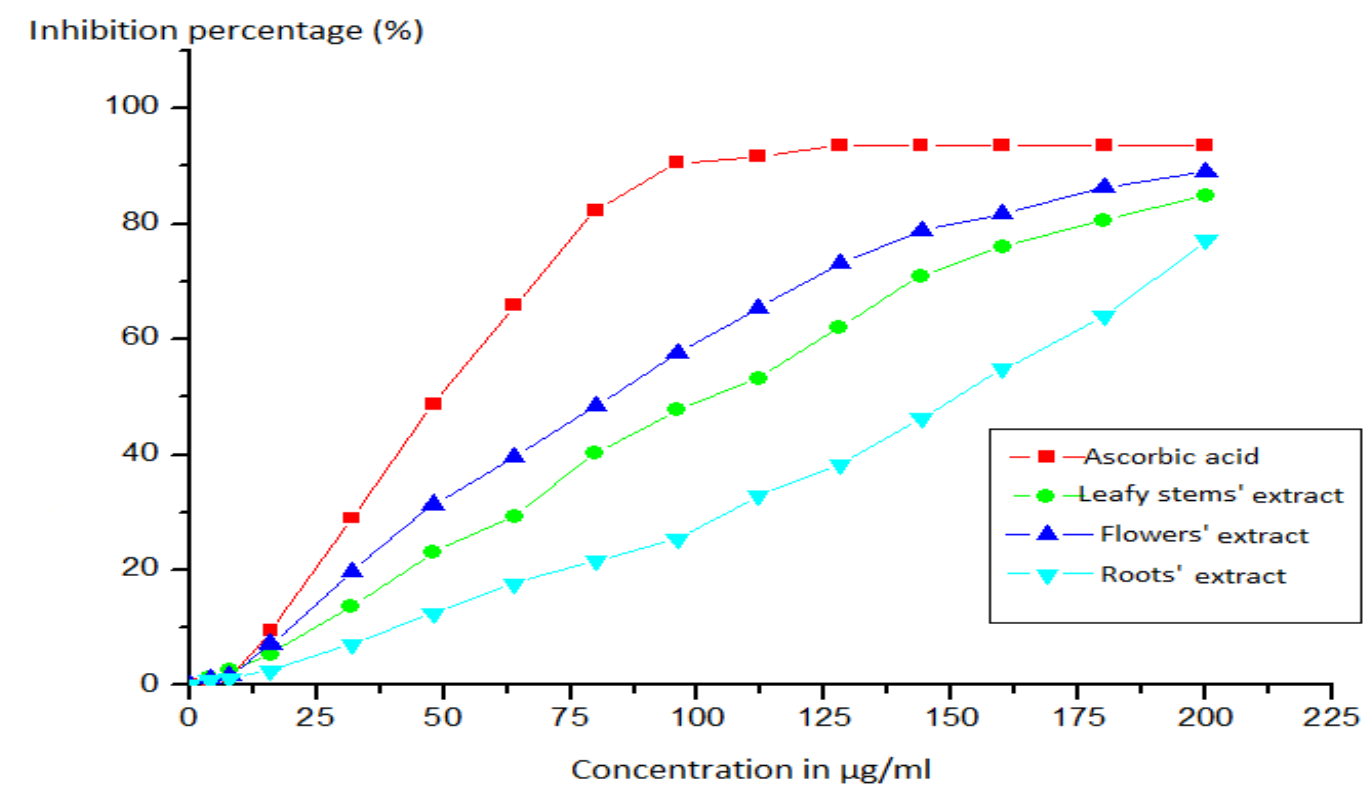

Picture3:- DPPH d'inhibitionpourcentages according to extracts concentrations

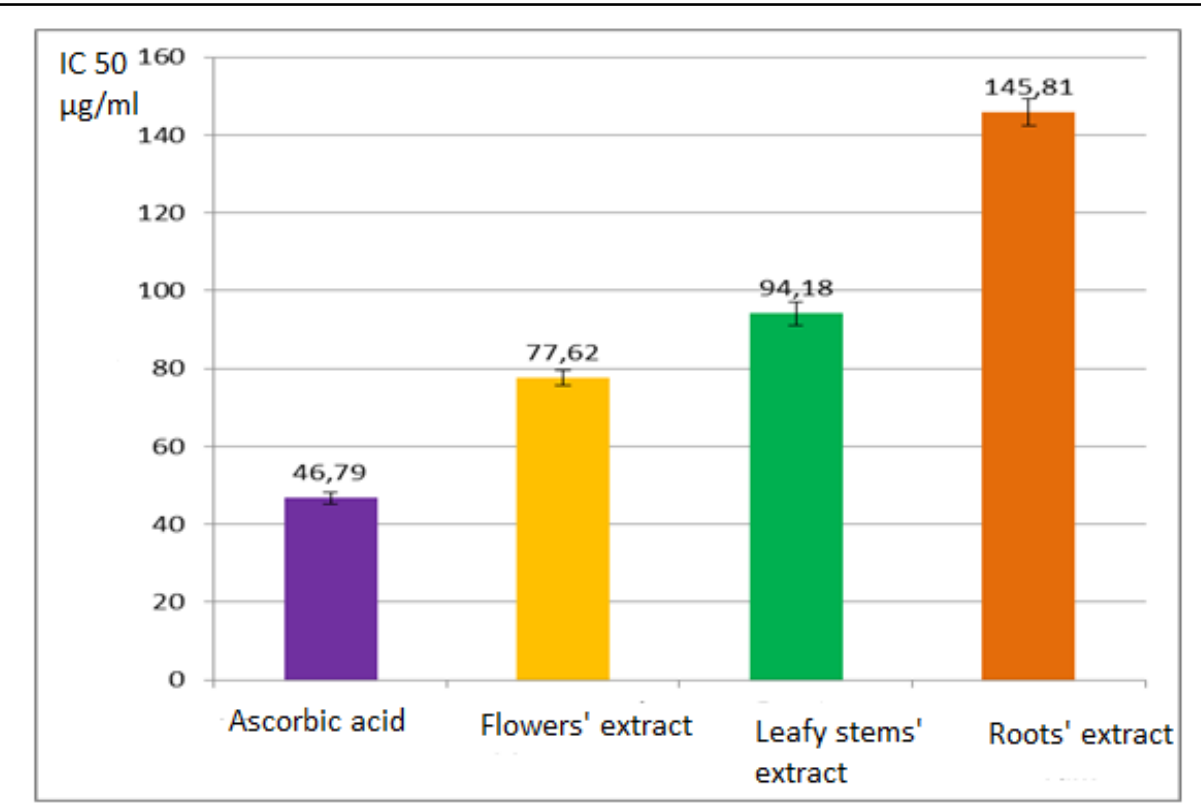

Picture4:- Half maximal inhibitoryconcentration (IC50) of hydro-methanol extracts towards DPPH

The results obtained show that hydro-methanol crude extracts of A. pyrethrum's organs have very important antioxidativeactivities, with IC50 $77.62 \mu \mathrm{g} / \mathrm{ml}$ for flowers, $94.18 \mu \mathrm{g} / \mathrm{ml}$ for leaves and $145.81 \mu \mathrm{g} / \mathrm{ml}$ for the roots. These levels are lower than that of ascorbic acid (IC50 $46.79 \mu \mathrm{g} / \mathrm{ml}$ ) used as a positive control (Picture 4).

On the other hand, we note that there is a correlation between the concentration of polyphenols and antioxidant activity, confirming that polyphenols are powerful antioxidants that inhibit the formation of free radicals and oppose oxidation of macromolecules. 
The antioxidant activity depends not only of the concentration of polyphenols, but also on the structure and nature of antioxidants in the extract [13]. Generally, polyphenols with high number of hydroxyl groups show highier antioxidant activity [25].

\section{Conclusion:-}

The phytochemical study of three organsofAnacyclus pyrethrum shows that the leaves and flowers are rich in tannins and flavonoids, while the roots are richer in alkaloids than both of the other parts of the plant.

Concerning the phenolic composition of the extracts, flowers and leaves showed high total polyphenol content in comparison with the roots.

This in vitro study of the antioxidant activity performed with the method of scavenging DPPH free radical showed that methanol crude extracts have a high capacity to trap the DPPH radical with 50\% inhibitory concentrations (IC50) about $77.62 \mu \mathrm{g} / \mathrm{ml}$ for flowers, $94.18 \mu \mathrm{g} / \mathrm{ml}$ for leaves and $145.81 \mu \mathrm{g} / \mathrm{ml}$ for roots. These extracts may therefore be an alternative to some synthetic additives-

It is therefore important to characterise and identify the bioactive molecules in all fractions of the three organs of A.pyrethrum by HPLC analysis.

\section{References:-}

1. Suhaj, M., 2006. Spice antioxidants isolation and their antiradical activity: a review.Journal of Food Composition and Analysis 19, 531-537.

2. Tadhani, M.B., Patel, V.H., et Subhash, R., 2007. In vitro antioxidant activities of Stevia rebaudiana leaves and callus. Journal of Food Composition and Analysis. 20, 323-329.

3. Koechlin-Ramonatxo C. (2006) Oxygen, oxidative stress and antioxidant supplementation, or another way for nutrition in respiratory diseases. Nutrition Clinique etMétabolique. 20, 165- 177.

4. Vârban D.I., Duda M., VârbanR.,etMuntean S. (2009) Research Concerning the Organic Technology for SaturejaHortensis L. Culture.Bulletin UASVM Agriculture. 66(2), 225- 229.

5. Bellakhdar, J., 1997. La Pharmacopée Marocaine Traditionnelle: Médecine arabe ancienne et savoirs populaires - Saint -Etienne, Edit. Ibis Press.

6. Ettahri Mohammed Ouadii. 2004: Importance économique et multiplication des plantes aromatiques et médicinales. Mémoire de troisième cycle en agronomie. Ecole Nationale d'Agriculture de Meknès.

7. Gattefosse J.,1921 Les vegetaux aromatiques de Madagascar. Agr. Colon4.,6 :1-9. Ministeredes Colonies Jardin Colonial

8. Charnot,A. La toxicologie au Maroc. Memoire de la societe des sciences naturelles a Rabat (Maroc), Edition Siege de l'I. S, Rabat, (1945) 717p.

9. Sujith K., Suba V., \& Darwin C R. 2011 a :Neuropharmacological profile of ethanolic extract of Anacyclus pyrethrum in albino wistar rats. International Journal Of Pharmaceutical Science And Research, 2(8), 21092114.

10. Choudhary, A, 2006 herbal medicine for cough and a tonic for heart, lungs and digestion and process for preparing the same. Indian Pat. Appl. IN 2005KO00732 A 20060324

11. PNUD, 2011. Document de projet Programme des Nations Unies pour le Développement, UNDP-GEF Medium-Size Projet, PIMS N4050 «Intégration de la biodiversité dans les chaines de valeur des Plantes Aromatiques et Médicinales Méditerranéennes au Maroc, Gouvernement de Maroc, p: 169.

12. K. N'Guessan, B. Kadja, G. N. Zirihi, D. Traore, \& L. Ake-Assi,2009 "Screening phytochimique de quelques plantes médicinales ivoiriennes utilisées en pays Krobou (Agboville, Côte-d'Ivoire)," Sciences \& Nature, vol. 6, no. 1, PP. 1-15

13. Soro, T.Y.Traore,F..Datte,J.Y\&. Nene-Bi,A.S,2009 "Activité antipyrétique de l'extrait aqueux de Ximenia americana," Phytothérapie, pp. 297-303

14. Bruneton,J. 1999 Pharmacognosie, Phytochimie, Plantes medicinales, Lavoisier Technique \& Documentation, 3ème édition,Paris,.

15. Bruneton,J.1993 Pharmacognosie, phytochimie, Plantes médicinales (2e édition), Tec et Doc., Lavoisier, Paris, pp. 915 ,.

16. Dohou,N. Yamni,K.Tahrouch,S. Hassani,L.Bodoc,A.\&Gmira,N.2003"Screening phytochimique d'une endemiqueIbero-marocain, Thymelaealytroides," Bull. Soc. Pharm. Bordeaux, pp. 61-78 
17. Bekro,Y .A. . Bekro,J. Boua,B. Tra,B. F. H. Ehile,E. E2007 "Etude ethnobotanique et screening phytochimique de Caesalpiniabenthamiana(Baill.) Herend. Et Zarucchi (Caesalpiniaceae)," Re. Sci. Nat., vol. 4, no. 2, pp. 217225

18. Traoré,F.2010. "Proposition de formulation d'un sirop antipaludique à base de argemonemexicana L. papaveraceae, " Thèsede doctorat, Faculté de Médecine, de Pharmacie et d'Odonto-Stomatologie du Mali, Université de Bamako, pp. 95

19. Falleh H., Ksouri R., Chaieb K., Karray-Bouraoui N., Trabelsi N., Boulaaba M., et Abdelly C.2008. Phenolic composition of Cynaracardunculus L. organs, and their biological activities. CompteRendu de Biologie. 331, 372-379.

20. Singleton V.L.et Rossi J.A. 1965Colorimetry of total phenolics with phosphomolybdic- phosphotungstic acid reagents. American Journal of Technology and Viticulture. 16, 144-153.

21. Hartmann T., 2007. From waste products to ecochemicals : Fifty years research of plant secondary metabolism. Phytochemisty ; 68: 2831 - 2846.

22. Popovici Cristina ; IlonkaSaykova ; BartekTylkowski, 2009. Evaluation de l'activité antioxydant des composés phénoliques par la réactivité avec le radical libre DPPH. Revue de génieindustriel 2009, 4, 2539

23. Maataoui B.S., Hmyene A., Hilati S.,2006Activites anti-radicalaires d'extraits de jus de fruits du figuier de Barbarie (Opuntia Ficus Indica). Libanese Science Journal, , 7(1), 3-7.

24. Bellakhdar J., (1996) La pharmacopée marocaine traditionnelle : Médecine arabe ancienne et savoirs populaires, Ibis Press, Paris, 177 p.

25. Hmamouchi M., (1999) Les plantes médicinales et aromatiques marocaines : utilisation, biologie, écologie, chimie, pharmacologie, toxicologie, lexiques, Imprimerie de Fédala, Rabat, 177 p.

26. Centre for MediterraneanCooperation, International Union for Conservation of Nature and Natural Resources, Union internationale pour la conservation de la nature et de ses ressources, (2005) A Guide to Medicinal Plants in NorthAfrica, pp. 31-32.

27. Selles C., Medjdoub H., El Amine Dib M., Zerriouh M., Tabti B., Anti-diabetic activity of aqueous root extract of Anacyclus pyrethrum L. in streptozotocin-induced-diabetic rats. Journal of Medicinal Plants Research, 2012, 6, pp. 3193-3198.

28. Limbachia H., Jadhav U., Phytochemical analysis and effect of antimicrobial activity of Cassia tora and Anacyclus pyrethrum. Plant Archives, 2012, 12, pp. 169-172.

29. Hamimed S., (2009). Caractérisation chimique des principes à effet antidermatophyte des racines d'Anacyclus pyrethrum L., Mémoire de Magister, 110 p.

30. Selles C., (2012). Valorisation d'une plante médicinale à activité antidiabétique de la région de Tlemcen : Anacyclus pyrethrum L. Application de l'extrait aqueux à l'inhibition de corrosion d'un acier doux dans $\mathrm{H} 2 \mathrm{SO} 4$ $0.5 \mathrm{M}$, Thèse de doctorat, pp. 83-91.

31. (Christian J.A., 2013) http://www.diade-research.fr/pages/equipes-de-recherche/smart.html (consulté le 21 juillet 2013).

32. Podsedek, A. (2007) Natural antioxidants and antioxidant capacity of Brassica vegetables: A review. LWT. 40:1-11.

33. Torres de pinedo, A., Pen alver, P.,Morales, J.C.2007. Synthesis and evalution of new phenolic-based antioxidant: structure-activity relationship.Food Chemistry, 103:55-61. 